\section{EFIKASNOST RAZNIH NASTAVNIH PRISTUPA NA UČINAK U ODBOJKAŠKOJ UTAKMICI}

\section{THE EFFECTIVENESS OF VARIOUS TEACHING APPROACHES ON THE PERFORMANCE OF THE VOLLEYBALL GAME}

\section{SAŽETAK}

Cilj ovog istraživanja je bio da se odredi $i$ potvrdi efikasnost raznih nastavnih pristupa na promjene $u$ nivou učinka u procesu držanja nastave iz odbojke učenicima u osnovnim školama. $U$ eksperimentalnoj grupi je korišten taktički pristup, a u kontrolnoj grupi tehnički (tradicionalni) pristup $u$ nastavi odbojke. Eksperimentalna grupa se sastojala od 26 učenika a kontrolna grupa od istog broja učenika. Obje grupe su predstavljale djevojčice koje pohađaju osnovnu školu uzrasta, 13-14 godina. Efikasnost nastavnog pristupa je procijenjena na osnovu učinka u igri. Učinak u igri je procijenjen metodom procjene učinka u igri, baziranog na GPAI (instrument za procjenu učinka u igri) kroz video zapise. Mann-Whitney U-test je korišten da se izvrši statistička procjena. Kada se procjenila taktička komponenta učinka igre "pozicija", dolazi se do zaključka da razlika između grupa nije statistički značajna (p>0.05). Poređenjem komponente "donošenje odluke" otkriveno je da razlika između postignutih učinaka u grupama statistički značajna $(p<0.05) \quad u$ korist eksperimentalne grupe. $U$ poređenju vještina izvršenja saznalo se da razlika između obje grupe u komponenti "serviranje" nije statistički značajna ( $>$ >0.05). Ali poređenjem dodavanja, smečovanja, ofanzivnog udarca $i$ učinka u igri tima dobila se statistički značajna $(p<0.05)$ razlika između obje grupe u korist eksperimentalne grupe. Prikupljeni podaci ukazuju na činjenicu da se, u ovom istraživanju, taktički pristup pokazao kao efikasniji metod za sticanje vještina igre i taktičkih komponenti igre.

Ključne riječi: odbojka, nastavni pristupi, učinak

\section{Jaroslav Popelka ${ }^{1}$ i Ratko Pavlović ${ }^{2}$}

${ }^{1}$ Katedra za fizičko vaspitanje i sport, Filozofski fakultet,

Matej Bel Univerzitet, Slovačka

${ }^{2}$ Fakultet fizičkog vaspitanja i sporta, Univerzitet $\mathrm{u}$ Istočnom Sarajevu, Bosna i Hercegovina

Originalni naučni članak doi:10.5550/sgia.171301.se.PP

UDK: 796.325 .01 COBISS.RS-ID 6759704

Primljeno: 12.04.2017. Odobreno: 23.06.2017.

Korespodencija: Jaroslav Popelka, PhD. Katedra telesnej výchovy a športu Tajovského 40 97404 Banská Bystrica Slovensko

Tel: 0484467554

Jaroslav.Popelka@umb.sk

Sportlogia 2017, 13 (1), 29-37.

E-ISSN 1986-6119 


\section{UVOD}

Danas je kvalitet procesa učenja jedan od glavnih razloga zašto djeca u osnovnim i srednjim školama nisu zanteresovana za fizičke aktivnosti. Drugi razlog je to što nastavnici i profesori nisu adekvatno pripremljeni i nisu u mogućnosti da motivišu učenike da se bave fizičkim aktivnostima u smislu didaktičkih stilova i nastavnih pristupa. Tematske jedinice sportskih igara (tradicionalne, netradicionalne) su među popularnim školskim aktivnostima fizičkog i sportskog obrazovanja u školi, sa najvećim brojem sati u školskom godišnjem rasporedu. Po mišljenju nekoliko autora (Zapletalová, Přidal i Laurenčík, 2007; Popelka, 2013), zadatak didaktičkog procesa u svakoj sportskoj igri, a samim tim i u odbojci, je da ovaj proces uči učenike da igraju najbrže i najefikasnije moguće, odnosno da dostignu kontinuirano ispoljavanje $u$ igri $i$ da se u učenicima probudi trajna zainteresovanost za igru. Ovo se može postići pomoću optimalnih pristupa nastave među kojima su metodi ogranizacionih formi, nastavni procesi, interakcija sa nastavnikom (Popelka, 2012a). Nekoliko autora (Thorpe, Bunker, i Almond 1986; Psotta i Velenský, 2001; Dobrý, 2003) je ustanovilo da prošla i sadašnja didaktika i praksa koriste razne pristupe nastave u nastavi sportskih igara. I u prošlosti i u sadašnjosti, u našem sistemu nastave sportskih igara, koristio se takozvani sistem tehničkog pristupa, koji je uglavnom fokusiran na vježbanje individualnih aktivnosti u igri i na kombinacije u igri, i tek nakon savladavanja ovih dijelova učenici mogu igrati samu igru. Ovaj model je kritikovan od strane nekoliko autora (Zat'ková, 2003; Lukavská, 2006) koji, kada su procjenjivali proces nastave u sportskim igrama, naglašavaju činjenicu da su učenici imali značajna ograničenja u sposobnosti igranja. Zemlje engleskog govornog područja uglavnom koriste taktički pristup u nastavi sportskih igara, koji je zasnovan na tome da se učenici podstiču da razumiju sve aspekte igre uz istovremeno uvećavanje fizičkog učinka, motivacije $i$ uživanja $u$ fizičkom obrazovanju (Popelka, 2012b). Ovaj model je poznat kao "Učenje igara u svrhu razumijevanja", stvoren od strane Bunker-a i Thorpe-a. Autori Alison i Thorpe (1997) i Blomqvist, Luhtanen i Laakso (2001) tvrde da su pomoću taktičkog pristupa u nastavi sportskih igara, učenici stekli taktičko znanje, vještine igre i razumjeli sve aspekte igre, dok su učenici koji su prisustvovali tradicionalnoj nastavi sa tehničkim pristupom poboljšali samo svoje vještine igre. Prema Popelka (2013), glavni argument za upotrebu ovog modela u nastavi, je da se poveća motivacija učenika da učestvuju u obaveznom fizičkom i sportskom obrazovanju. Drugo istraživanje autora (Turner i Martinek, 1992; Rink, 1996) je poredilo oba pristupa u nastavi sportskih igara, i nije otkrilo ikakve značajne razlike između gore spomenutih pristupa nastave. Njihov istraživački rad se poklapa sa činjenicom da su učenici koji su učestvovali u taktičkom nastavnom pristupu izrazili veće zadovoljstvo i pokazali isti napredak u tehnici, kao i u samoj igri. Kada su uporedile određeno znanje, ni Olosová ni Zapletalová (2014) nisu utvrdile veću efikasnost modela taktičke nastave u poređenju sa tehničkim modelom. Nekoliko autora se

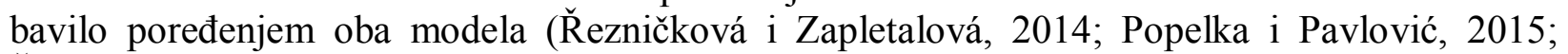
Žuffová i Zapletalová, 2015), a ovaj rad se takođe bavi empirijskom potvrdom i poređenjem obrazovnih efekata tehničkih i taktičkih modela nastave na učinak učenika u odbojci u osnovnim školama. Cilj ovog istraživanja bio je da se uporedi efikasnost raznih nastavnih pristupa na učinak učenika u odbojci u osnovnim školama. 


\section{METODE}

U ovom istraživanju koristio se pedagoški eksperiment sa dvije grupe koje su predstavljale djevojčice uzrasta 13-14 godina. Istraživanje se odvijalo od januara 2016. do marta 2016 godine. Eksperimentalna grupa se sastojala od 26 učenica, a kontrolna grupa je imala isti broj učenica. Istraživanje je obavljeno u toku 17 časova, od kojih su obje grupe trenirale odbojku 15 časova. Prvi i posljednji čas su bili namijenjeni da procijene učinak u igri. Tokom 8 sedmica istraživanja, u eksperimentalnoj grupi je korišten taktički nastavni pristup, a u kontrolnoj grupi je korišten tehnički pristup, dva puta sedmično po 45 minuta na časovima odbojke.

Nastava sa taktičkim pristupom: osnovni dio časa je počinjao sa modifikovanom igrom. Nakon modifikovane igre, odvijala se diskusija gdje je nastavnik postavljao pitanja učenicima. Učenici su pokušavali da pronađu odgovore na pitanja. Onda je nastavnik odabrao druge modifikovane igre. Učenici su najčešće igrali modifikovane igre 2 na 2, 3 na 3, 4 na 4, 5 na 5, 6 na 6, a najmanje su radili vježbe tehnike. Nastava sa tehničkim pristupom: svaki osnovni dio časa je počinjao sa vježbom tehnike. Prije treninga, nastavnik je objašnjavao tehnike vještine, taktičku upotrebu u igri i onda se odvijao meč. U tehničkom pristupu nastavi dominantne su bile tehnike vježbanja, 6 na 6 igre, a najmanje dominantna je bila modifikovana 3 na 3 igra.

Poređenje korištenja specifičnih taktičkih i tehničkih pristupa je predstavljeno u tabeli 1.

Tabela 1 Poređenje upotrebe specifičnosti nastavnih pristupa

\begin{tabular}{|c|c|c|c|c|c|c|c|c|c|}
\hline \multirow{3}{*}{$\begin{array}{l}\text { Nastavni } \\
\text { pristup }\end{array}$} & \multirow{3}{*}{ Grupa } & \multicolumn{8}{|c|}{ Specifičnosti nastave } \\
\hline & & \multirow{2}{*}{$\begin{array}{l}\text { Vježbe } \\
\text { tehnike }\end{array}$} & \multirow{2}{*}{$\begin{array}{c}\text { Modifikovane } \\
\text { igre }\end{array}$} & \multirow{2}{*}{$\begin{array}{c}\text { Zvanična } \\
\text { igra }\end{array}$} & \multicolumn{5}{|c|}{ Didaktički stilovi } \\
\hline & & & & & 1 & 2 & 3 & 4 & 5 \\
\hline $\begin{array}{l}\text { Taktički } \\
\text { pristup }\end{array}$ & $\begin{array}{c}\text { Eksperimentalna } \\
\text { grupa }\end{array}$ & $6,70 \%$ & $73,3 \%$ & $20 \%$ & $11,8 \%$ & $0 \%$ & $35,3 \%$ & $71 \%$ & $64,7 \%$ \\
\hline $\begin{array}{l}\text { Tehnički } \\
\text { pristup }\end{array}$ & Kontrolna grupa & $46,7 \%$ & $13,3 \%$ & $40 \%$ & $58,8 \%$ & $24 \%$ & $0 \%$ & $0 \%$ & $41,2 \%$ \\
\hline
\end{tabular}

Napomene: 1 - didaktički stil naređenja, 2 - didaktički stil prakse, 3 - didaktički stil sa ponudom, 4 - didaktički stil sa kontrolisanim otkrivanjem, 5 - didaktički stil sa samostalnim otkrivanjem

Napomena: Procenat korištenja didaktičkih stilova predstavlja realan broj specifičnosti nastave na časovima (koristili smo nekoliko didaktičkih stilova na jednom času)

U ovom istraživanju predstavljene su informacije koje sadrže nivo učinka u igri odbojke učenika u eksperimentalnoj i kontrolnoj grupi. Korišten je metod posmatranja za planirano i namjerno posmatranje kvantiteta i kvaliteta taktičkih i tehničkih komponenti igre da bi se dobili podaci. Komponente učinka u igri su analizirane uz pomoć audio-vizuelne opreme. Selekcija procijenjenih komponenti igre i kriterijum njihove procjene je zasnovan na procjeni učinka u igri (prema Mitchell, Oslin i Griffin, 2006). Procjenjivanje učinka u igri se odvijalo na posljednjem času, gdje je svaki učenik igrao 20 minuta. Ocjenjivane su sposobnost donošenja odluke, pozicija i izvršavanje vještina.

\section{Komponente igre i kriterijumi:}

Donošenje odluke: Učenik koristi tačnu vještinu u tačno vrijeme.

Ključ za bodovanje:

Prikladno: Učenik koristi tačnu vještinu u tačno vrijeme (dodavanje podlakticom na prvi dodir; volej iznad glave na drugi dodir; udarac na treći dodir).

Neprikladno: Učenik ne koristi tačnu vještinu u tačnom momentu (udarac na drugi dodir) 
Pozicija: Nakon udaranja lopte, učenik treba da zauzme određenu poziciju na terenu.

Ključ za bodovanje:

Prikladno - nakon udaranja lopte, učenik će se vratiti na prikladnu poziciju da bi imao optimalnu pokrivenost terena.

Neprikladno - nakon udaranja lopte, učenik ne zauzima prikladnu poziciju da bi imao optimalnu pokrivenost terena.

Izvršenje vještine: Učenik dodaje loptu pravilno (lopta stiže do namijenjene mete)

Ključ za bodovanje:

Smečovanje, dodavanje

Efikasno - Učenik udara loptu u skladu sa pravilima, tehnički ispravno i smečuje, prosljeđuje loptu saigraču.

Neefikasno - Učenik ne udara loptu u skladu sa pravilima, tehnički neispravno i ne smečuje ili ne prosljeđuje loptu svom suigraču.

\section{Ofanzivni udarac}

Efikasno - Učenik udara loptu u skladu sa pravilima i tehnički ispravno.

Neefikasno - Učenik ne udara loptu u skladu sa pravilima i tehnički neispravno.

Serviranje

Efikasno - Učenik servira loptu u skladu sa pravilima i tehnički ispravno.

Neefikasno - Učenik ne servira loptu u skladu sa pravilima i tehnički neispravno.

Za procjenu rezultata, korišten je Mann-Whitney U test za samostalne selekcije i deskriptivne statistike. Značajnost je određena standardno koristeći 5\% nivo $(\mathrm{p}<0.05)$.

\section{REZULTATI}

Poređenje učinka u igri tima u eksperimentalnoj i kontrolnoj grupi je predstavljeno u tabeli 2.

Tabela 2 Poređenje procjene učinka igre kontrolne i eksperimentalne grupe

\begin{tabular}{|c|c|c|c|c|c|c|c|}
\hline $\begin{array}{c}\text { Poređenje } \\
\text { grupa }\end{array}$ & O & P & Se & D & Sm & Ou & UTI \\
\hline Eg & $73.30 \%$ & $74 \%$ & $67.50 \%$ & $70.20 \%$ & $68.30 \%$ & $70.10 \%$ & $71.40 \%$ \\
\hline Kg & $62.10 \%$ & $65.20 \%$ & $60.30 \%$ & $53 \%$ & $50 \%$ & $52.80 \%$ & $57.20 \%$ \\
\hline M-W & 0.010 & 0.132 & 0.147 & 0.025 & 0.014 & 0.017 & 0.001 \\
\hline
\end{tabular}

Napomena objašnjenja: Eg - eksperimentalna grupa, $\mathrm{Kg}$ - kontrolna grupa, $\mathrm{M}-\mathrm{W}$ - Mann Whitney U test $\mathrm{p}<0.05, \mathrm{O}-$ odluka o tome "šta" raditi, P - pozicija nakon udarca, Se - serviranje, D - dodavanje, Sm - smečovanje, Ou - ofanzivni udarac, UTI učinak tima u igri

Poređenjem donošenja odluke otkriveno je da je razlika između dostignutog učinka u grupama $11.2 \%$ u korist eksperimentalne grupe, statistički značajna $(\mathrm{p}<0.05)$. Dakle, može se tvrditi da je 
eksperimentalna grupa značajno bolja u procjeni komponente taktičke igre o tome "šta" će učenik demonstrirati. Uzimajući u obzir već spomenute činjenice, može se konstatovati da su učenici u eksperimentalnoj grupi pokazali bolju mogućnost da donesu pravu odluku u različitim situacijama u igri. Pretpostavlja se da su učenici stekli ovu sposobnost zahvaljujući broju modifikovanih igara u kojima su takođe morali ispuniti taktičke zadatke.

Poređenjem učinka u poziciji, otkrilo se $8.8 \%$ razlika između grupa u korist eksperimentalne grupe. Uprkos činjenici da je taktički nastavni pristup korišten u eksperimentalnoj grupi, u ovom slučaju razlika između grupa nije statistički značajna ( $p>0.05)$. Pretpostavilo se da će učenici $u$ eksperimentalnoj grupi postići statistički značajne razlike u poređenju sa kontrolnom grupom, dok će učenici u eksperimentalnoj grupi imati više prilika za rješavanje aspekata taktičke igre zbog činjenice da su igrali modifikovane igre. U takvim igrama nastavnik je postavljao pitanja kao što je: "Na kom dijelu terena treba da stojiš nakon što udariš loptu?", koje je u ovom slučaju dovelo do odabira ispravne pozicije na terenu nakon udaranja lopte.

Razlika u serviranju između grupa je 7.2\% u korist eksperimentalne grupe. Takva razlika nije statistički značajna $(\mathrm{p}>0.05)$. Pretpostavilo se da eksperimentalni podsticaj nije značajno doprinjeo učenju i napretku u serviranju, jer su učenici češće servirali na kraće razdaljine. Uprkos činjenici da serviranje nije pokazalo statistički značajne razlike, smatra se da je sposobnost da se nose sa stresom tokom igre važan uslov uspjeha. Pretpostavilo se da eksperimentalna grupa, koja je igrala raznovrsne modifikovane igre, može bolje da se nosi sa stresom i da će učenici kao pojedinci igrati bolje.

Poređenjem dodavanja između grupa razlika je bila 17.2\% u korist eksperimentalne grupe, što je statistički značajno $(\mathrm{p}<0.05)$. Na osnovu postignutog učinka u dodavanju, pretpostavlja se da je eksperimentalni podsticaj imao uticaj na ovu defanzivnu aktivnost $u$ igri u pozitivnijem smislu. Treba naglasiti da je nivo savladavanja ove aktivnosti u igri pojedinaca veoma nizak u kontrolnoj grupi. Ako igrači ne mogu pravilno da dodaju jedni drugima, na tom nivou učinka teško je da smečer doda loptu za udarac.

Poređenjem smečovanja između grupa razlika je 18.3\% u korist eksperimentalne grupe, što je statistički značajno $(\mathrm{p}<0.05)$. Pretpostavlja se da je učinak smečovanja u kontrolnoj grupi značajno pod uticajem prethodne aktivnosti u igri - dodavanja. Pretpostavka je da kada bi dodavanje bilo bolje, kontrolna grupa bi postigla bolji učinak u smečovanju i napadu.

Poređenjem ofanzivnog udarca između grupa razlika je 17.3\% u korist eksperimentalne grupe, što je statistički značajno $(\mathrm{p}<0.05)$. Pretpostavlja se da je broj mečeva sa manje igrača omogućio učenicima u eksperimentalnoj grupi da budu češće u kontaktu sa loptom u ofanzivnoj fazi i shodno tome da postignu uspješne ofanzivne udarce.

Procjenom učinka igre tima razlika je 14.2\% u korist eksperimentalne grupe. Ova razlika je statistički značajna $(\mathrm{p}<0.05)$. Igra odbojke je okarakterisana uticajem prethodnih aktivnosti pojedinca i uticaja nad sljedećom aktivnošću. Ovo je takođe potvrđeno ovim istraživanjem. Shodno tome, dodavanja i smečovanja u eksperimentalnoj grupi su imala veću stopu uspješnosti od približno $70 \%$, a ofanzivni udarac je imao 70.10\% stopu uspješnosti. Sve aktivnosti u igri pojedinca u kontrolnoj grupi su bile tek iznad 50\% a time je stopa uspješnosti ofanzivnog udarca je bila 52.8\%. Iz postignutih rezultata može se zaključiti da je, sa tačke gledišta statističke značajnosti, eksperimentalna grupa bila bolja samo u jednoj komponenti taktičke igre, a to je "donošenje odluke". Zanimljivo je, da u drugoj taktičkoj komponenti "pozicija", eksperimentalna grupa nije postigla bolje rezultate u poređenju sa kontrolnom grupom. S druge strane, procjenom ove taktičke komponente, eksperimentalna grupa je postigla $8.8 \%$ bolji učinak.

Popelka, J. \& Pavlović, R.: Efikasnost raznih... Sportlogia 2017, 13 (1), 29-37. Stranica 33. 


\section{DISKUSIJA}

Nekoliko autora (Alison i Thorpe, 1997; Blomqvist, Luhtanen i Laakso, 2001) je otkrilo $\mathrm{da} \mathrm{u}$ pogledu taktičkog pristupa, $\mathrm{u}$ poređenju sa tradicionalnom nastavom, učenici su $\mathrm{u}$ mogućnosti da prošire njihovo taktičko razmišljanje i sposobnost da donose dobre odluke u toku igara. Ova tvrdnja je statistički značajna $(p<0.05)$, što je dokazano oviim istraživanjem kao procjenom taktičke komponente igre "donošenje odluke". Ovo znači da su učenici u eksperimentanoj grupi bili u mogućnosti da donesu bolju odluku o tome "šta" treba da urade i "kako da to urade" (da izaberu tehniku). Međutim, nisu bili bolji u odabiru ispravne pozicije na terenu nakon udarca lopte, iako je razlika koja je izražena u procentima u korist eksperimentalne grupe. Pretpostavlja se da su učenici u eksperimentalnoj grupi bili sposobni da donesu bolje odluke na osnovu raznovrsnosti modifikovanih igara koje su igrali 2 na 2, 3 na 3, u kojima su tehički zahtjevi (Light, 2010) umanjeni tako da učenici mogu učestvovati u igri. U isto vrijeme naglasak je stavljen na taktiku igre i razvoj fizičkih vještina. Psott (2002) je naveo da modifikovane igre podržavaju kognitivne aktivnosti učenika i zahtijevaju korištenje odgovarajućih didaktičkih stilova nastave, što se potvrdilo u ovom istraživanju. Iz tog razloga su $\mathrm{u}$ ovom istraživanju korišteni različiti didaktički stilovi, koji se preklapaju sa kognitivnim pragom. Na primjer, nakon modifikovane igre, provođena je diskusija u kojoj je nastavnik postavljao pitanja učenicima. Učenici su pokušavali da nađu odgovore na pitanja. Ovi didaktički stilovi se smatraju odlučujućim aspektima obrazovanja po Webb, Pearson i Forrest (2009). Griffin, Mitchell i Oslin (1997) navode da učinak zavisi od donošenja taktičkih odluka, tj. sposobnosti da se identifikuje problem i pronađe rješenje u datoj situaciji u igri. Na osnovu zapažanja procjene nivoa učinka u igri može se zaključiti da je ekperimentalna grupa kojoj je držana nastava kroz taktički pristup, dostigla statistički značajan $(\mathrm{p}<0.05)$ bolji kvaliltet učinka u igri od kontrolnih grupa. Ranije je Kuchárik (2014) pružio slične rezultate u malom rukometu i Žuffová (2012) u ultimativnom frizbiju. Nakon procjene obje grupe u pojedinačnim aktivnostima $\mathrm{u}$ igri, statistički značajne $(\mathrm{p}<0.05)$ razlike $\mathrm{u}$ tehnikama dodavanja i smečovanja su potvrđene $\mathrm{u}$ korist eksperimentalne grupe. Neki autori (Fraňo, 1994; Zapletalová i Čabajová, 2001) tvrde da je analitičko-sintetički metod koji se preferira u tehničkom pristupu efikasniji u učenju i poboljšavanju ofanzivnog udarca. U ovom istraživanju ova tvrdnja nije potvrđena, jer se poređenjem ofanzivnih udaraca pronašla statistički značajna $(\mathrm{p}<0.05)$ razlika između grupa $u$ korist eksperimentalne grupe. Pretpostavka je da su brojne modifikovane igre omogućile eksperimentalnoj grupi da dobije bolji ofanzivni udarac, jer su svi učenici često u dodiru sa loptom i mogu učestvovati u stvarnoj situaciji u igri. Statistički značajna razlika između obje grupe nije zabilježena samo kad se servira i može se konstatovati da je nivo savladavanja ove tehnike jednak u obje grupe. Ono što je zajedničko za ove grupe je da su najuspješnije bile u serviranju. Ovo može biti objašnjeno činjenicom da je serviranje jedinstvena aktivnost u odbojci, izvršena pod standardnim uslovima (Hančík, Mašlejová i Tokár, 1994; Zapletalová i Přidal, 1996), tj. serviranje nije pod uticajem kvaliteta prethodne aktivnosti u igri. Rezultati dobijeni u ovom istraživanju ne mogu biti generalizovani. Drugi autori istraživanja (Turner i Martinek, 1992; Rink, 1996) su poredili oba nastavna pristupa u nastavi sportskih igara i nisu otkrili značajne razlike u prethodno spomenutim nastavnim pristupima.

Popelka, J. \& Pavlović, R.: Efikasnost raznih... Sportlogia 2017, 13 (1), 29-37. Stranica 34. 


\section{ZAKLJUČAK}

Rezultatidobijeni ovim istraživanjem predstavljaju samo dio predmeta debate o poređenju efikasnosti raznih nastavnih pristupa sa učinkom učenika osnovne škole u igri. Sa obrazovne tačke gledišta koristištene su, uglavnom, modifikovane igre sa manje igrača (2 na 2, 3 na 3$) \mathrm{u}$ kojima su se primarno koristili didaktički stilovi u kontrolisanom otkrivanju, didaktički stilovi sa samostalnim otkrivanjem i didaktički stil sa ponudom. Istraživanjem se ukazalo na to da se, sa kompleksne tačke gledišta, pokazalo da je taktički nastavni pristup najpogodniji metod učenja vještina igre i komponenti taktičke igre. U skladu sa predstavljenim rezultatima, može se predložiti sljedeće za praksu: korištenje vježbi, zasnovanih na situacionom kontekstu igre, i korištenje nekoliko različitih didaktičkih stilova u jednom razredu.

\section{LITERATURA}

Alison, S., \& Thorpe, R. (1997). A comparison of the effectiveness of two approaches to teaching games within physical education. A skills approach versus a games for understanding approach. The British Journal of Physical Education, 28 (3), 9-13.

Blomqvist, M., Luhtanen, P., \& Laakso, L. (2001). Comparison of Two Types of Instruction in Badminton. In European Journal of Physical Education, 6(2),139-155. https://doi.org/10.1080/1740898010060206

Dobrý, L. (2003). Jak spojit myšlení a pohyb v basketbalovom nácviku. In Tělesná výchova a sport mládeže, 69(4), 25- 30.

PMid:12689238

Fraňo, J. (1994). K vyučovacím postupom pohybových činností. In Telesná výchova \& Šport, 4(4), 5 - 7.

Griffin, L., L., Mitchel, S., A., \& Oslin, J. (1997). Teaching Sport Concepts and Skills: A Tactical Games Aproach. Retrived from http://classdat.appstate.edu/CHS/HLES/townsnd js/PE\%203009\%20\%20Survey\%20of\%20Sport/Sportfolio/Cricket/Additional\%20Resources/ Assessing\%20O utcomes\%20-\%20GPAI.PDF.

Hančík, V., Mašlejová, D., \& Tokár, J. (1994). Teória a didaktika športovej špecializácie a zvoleného športu volejbal. Bratislava, SL: Univerzita Komenského, Fakulta telesnej výchovy a športu. ISBN 80-223-0584-7.

Kuchárik, I. (2014). Efektivita taktického a technického didaktického prístupu pri výučbe mini-hádzanej 1. až 5. ročníka základných škôl. Bratislava, SL. Diplomová práca. Univerzita Komenského v Bratislave, Fakulta telesnej výchovy a športu, Katedra športových hier.

Lukavská, M. (2006). Výuka volejbalu na středních školách. In Hry 2006: Výzkum a aplikace : sborník referátu ze 7. mezinárodní vedecké konference. Plzeň, CH: Západočeská univerzita. ISBN 807043-4430, s. 40-44.

Light, R. (2010). Implementing pedagogical innovation in physical education: A case study on the implementation of TGfU pedagogy in a NSW Secondary School. Retrived from $<$ http://www.barker.nsw.edu.au/ subsite.asp?ss=105\&id=4\&pg=9>

Mitchell, S., Oslin, J., \& Griffin, L. (2006). Teaching Sports and Skills: A TActical Games Approach. Second edition. Champaing, IL : Human Kinetics, 560-565. ISBN-13: 9780736054539.

Olosová, G., \& Zapletalová, L. (2014). Effects of a Teaching Games for Understanding Approach and Tactical Approach to Teaching Basketball on Declarative and Procedural Knowledge. In: International scientific conference Sports, Physical Activity and Health. Proceedings. Bratislava: Slovak Scientific Society for Physical Education and Sports, 191-194. ISBN 978-80-89075-44-7.

Popelka, J. (2012a). Porovnanie rôznych prístupov vyučovania na úroveň rozvoja techniky odbitia zdola vo volejbale na II. stupni základnej školy. Exercitatio corporis - motus - salus. 4, (2), 124-130. ISSN 1337-7310. 
Popelka, J. (2012b). Vplyv špecifického programu na zmeny úrovne hernej výkonnosti žiakov vo vyučovaní volejbalu na II. stupni základných škôl: dizertačná práca. Banská Bystrica, SL: Fakulta humanitných vied.

Popelka, J. (2013). Comparison of tactical and technical teaching approaches and their influence on the level of volleyball performance of pupils aged 13 and 14. Sport Scientific And Practical Aspects, $10(2), 13-17$.

Popelka, J., \& Pavlović, R. (2015). A comparison of different teaching approaches and their impact on the level of theoretical knowledge of volleyball among 13-14 year old pupils. Sport Scientific And Practical Aspects, 12(1), 5-9.

Psotta, R. (2002). Vytváření učebních podmínek pro vyučování sportovním hrám. In Tělesná výchova a sport mládeže, 68(5), 23 - 29.

Psotta, R., \& Velenský, M. (2001). Alternativní vyučování sportovních her ve školní tělesné výchově (I). Tělesná výchova a sport mládeže, 67(5), 42-46.

Rink, J. (1996). Tactical and skill approaches to teaching sport and games: Introduction. Journal of Teaching in Physical Education, 15, 397-398. https://doi.org/10.1123/jtpe.15.4.397

Řezníčková, L., \& Zapletalová, L. (2014). Výučba výberového tematického celku bedminton. In Telesná výchova \& Šport, 24(4), 35- 39.

PMCid:PMC4072890

Thorpe, M., Bunker, D., \& Almond, L. (1986). Rethinking Games Teaching. Loughborough: Department of Physical Education and Sport Science, Retrived from $<$ http://www.tgfu.org/articles/PHED\%20 RETHINKING\%20GAMES.pdf>

Turner, A., \& Martinek, T. (1992). A comparative analysis of two models for teaching games (technique approach and game centered (tactical focus) approach). International Journal of Physical Education, 24, 131- 152.

Webb, P., Pearson, P., \& Forrest, G. (2009). Expanding the teaching games for understanding (TGfU) concept to include sport education in physical education program (SEPEP). Retrived from $<$ http://ro.uow.edu.au/cgi/viewcontent.cgi?article=1094\&context=edupapers $>$

Zapletalová, L., \& Čabajová, M. (2001). Nácvik a zdokonal'ovanie smeča v školskej telesnej výchove. In Športové hry, 6(2), $31-40$.

Zapletalová, L., \& Přidal, V. (1996). Teória a didaktika volejbalu. Bratislava, SL: Univerzita Komenského, Fakulta telesnej výchovy a športu, 108 s. ISBN 80-967456-1-1.

Zapletalová, L., Přidal, V., Laurenčík, T. (2007). Volejbal. Základy techniky, taktiky a výučby. 1. vyd., Bratislava, SL: Univerzita Komenského, 158 s. ISBN 978-80-223-2280-5.

Zat'ková, V. (2003). Využitie sút'aživých foriem pri zdokonal'ovaní prihrávok v extraligovom družstve v hádzanej. Športové hry, 8(1), 8 - 12.

Žuffová, Z. (2012). Efektivita rôznych prístupov $k$ vyučovaniu frisbee ultimate. Bratislava, SL. Diplomová práca. Univerzita Komenského v Bratislave, Fakulta telesnej výchovy a športu, Katedra športových hier.

Žuffová, Z., \& Zapletalová, L. 2015. Efficiency Of Different Teaching Models In Teaching Of Frisbee Ultimate. Acta Facultatis Educationis Physicae Universitatis Comenianae, 55(1), 64-73. https://doi.org/10.1515/afepuc-2015-0008 


\section{SUMMARY}

The aim of the study was to determine and verify the effectiveness of various teaching approaches on changes in the level of volleyball performance in the process of teaching volleyball to pupils in primary schools. In the experimental group was used the tactical approach and in the control group the techniques (traditional) approach in teaching of volleyball. The experimental group consisted of 26 pupils and the control group consisted same number of pupils. Both groups, representing 13 to 14 year old schoolgirls in primary school. Efficiency of the teaching approaches was evaluated based of game performance. Game performance was evaluated by the method of game performance assessment based on GPAI (Game Performance Assessment Instrument) through video record. To perform statistical evaluation Mann-Whitney U-test was used. When we evaluate the tactical component of game performance "position", we found out that the difference between groups is not statistically significant $(p>0.05)$. By comparison "decision-making" it was discovered that the difference, between achieved performances in groups it is statistically significant $(p<0.05)$ in favour of the experimental group. By comparison skills execution we found out, that the difference between both groups in "serving" is not statistically significant $(p>0.05)$. But by comparison of passing, setting, offensive hit and team's game performance" we found out statistically significant $(p<0.05)$ the difference between both groups in favour of the experimental group. The acquired data pointed to the fact that in generally the tactical teaching approach appears to be a more efficient method for acquiring game skills and tactical components of the game.

Key words: volleyball, teaching approaches, performance 